\title{
MicroRNA-125a Regulates Cell Proliferation Via Directly Targeting E2F2 in Osteosarcoma
}

\author{
Tieying Tao ${ }^{\mathrm{a}}$ Qinrong Shen ${ }^{\mathrm{a}}$ Jianmin Luo ${ }^{\mathrm{b}}$ Yang $\mathrm{Xu}^{\mathrm{a}} \quad$ Wenqing Liang ${ }^{\mathrm{b}}$ \\ aDepartment of Orthopedics, Shaoxing Hospital of Traditional Chinese Medicine, Shaoxing, \\ 'Department of Orthopedics, Shaoxing Hospital of Zhejiang University, Shaoxing, P.R. China
}

\section{Key Words}

MicroRNA-125a • E2F2 • Osteosarcoma • Tumor suppressor

\begin{abstract}
Background/Aims: Increasing evidence has shown that miR-125a plays important role in human cancer progression. However, little is known about the function of miR-125a in osteosarcoma. Methods: The expression of miR-125a in osteosarcoma tissues and cell lines were examined by qRT-PCR. The biological role of miR-125a in osteosarcoma cell proliferation was examined in vitro. The targets of miR-125a were identified by a dual-luciferase reporter assay. Results: The results showed that the expression of miR-125a expression is significantly lower in osteosarcoma tissues and cell lines. Survival curves showed that the survival of patients in high miR-125a expression was significantly longer than that of patients with low miR-125a expression, and multivariate analysis suggested that miR$125 \mathrm{a}$ is an independent prognostic factor for osteosarcoma patients. In addition, it was found in this study that miR-125a can inhibit the growth of osteosarcoma cells. The dualluciferase reporter assay demonstrated that E2F2 is a novel target gene for miR-125a. In addition, in a recovery experiment, it was shown that miR-125a inhibits the biological function of osteosarcoma cells by inhibiting the expression of E2F2. Conclusion: Our results suggest that miR-125a acts as a tumor suppressor via regulation of E2F2 expression in osteosarcoma progression, and miR-125a may represent a novel therapeutic target for the treatment of osteosarcoma.
\end{abstract}

(C) 2017 The Author(s)

Published by S. Karger AG, Basel

\section{Introduction}

Osteosarcoma often occurs in young adults and children and is a common primary malignant tumor of bone [1]. It is characterized by a high degree of malignancy, frequent distant metastasis and low long-term survival rate [1]. According to statistics, the 5-year survival rate of patients with osteosarcoma treated with surgery alone is approximately 


\section{Cellular Physiology Cell Physiol Biochem 2017;43:768-774 \begin{tabular}{l|l|l} 
and BOI: 10.1159/000481560 & $\begin{array}{l}\text { C } 2017 \text { The Author(s). Published by S. Karger AG, Basel } \\
\text { www.karger.com/cpb }\end{array}$
\end{tabular}}

Tao et al.: MiR-125a Suppresses OS by Inhibiting E2F2

$16 \%$ [2]. Osteosarcoma often occurs in the metaphysis of long bones of limbs [3]. The initial treatment of osteosarcoma mainly involves surgical amputation, but this surgery has a high likelihood of trauma, high morbidity and low long-term survival rate. With the development of surgery and preoperative and postoperative chemotherapy, the clinical remission rate and long-term survival rate of osteosarcoma have greatly improved in recent times $[3,4]$. Despite improvements in surgery and neoadjuvant chemotherapy, the clinical prognosis of most patients is still poor [2]. At present, the exact mechanism for the development and progression of osteosarcoma remains unclear; thus, clarifying the molecular mechanism of osteosarcoma development is important for its diagnosis and treatment.

miRNAs are small, non-coding RNAs discovered in recent years that play an important regulatory role in the development and progression of tumors [5]. They inhibit the transcription of key tumor-related genes and down-regulate their expression via binding to complementary 3' un-translated region (3'UTR) sequences on the corresponding mRNAs. Studies have shown that abnormal expression of miRNAs is closely related to biological behaviours of osteosarcoma, such as proliferation, metastasis and prognosis [6]. miR-125a is an miRNA that has been recently studied and recognized as a tumor suppressor [7-13]. miR-125a plays an important role in various cell processes, such as cell differentiation, proliferation and apoptosis, by regulating different target genes. However, the expression of miR-125a in osteosarcoma and its role in the development of this disease are unclear. This study aimed to investigate the expression of miR-125a in osteosarcoma and its relationship with prognosis and to study the biological effect and regulatory mechanism of miR-125a in osteosarcoma cells.

\section{Materials and Methods}

\section{Patients and tumor tissues}

A total of 65 paired fresh surgically resected osteosarcoma tumor tissues and adjacent non-tumor tissues were obtained from Shaoxing Hospital of Zhejiang University between November 2007 and November 2010. The specimens were immediately frozen in liquid nitrogen and stored at $-80^{\circ} \mathrm{C}$ until use. Both tumor and non-tumor samples were confirmed by pathological examination. The patients' characteristics are summarized in Table 1. This study was approved by Shaoxing Hospital of Zhejiang University according to the Declaration of Helsinki. Written informed consent was obtained from all participants.

\section{Cell culture and transfection}

Osteosarcoma cells lines including MG-63, U2OS, HOS and Saos-2 were obtained from American Type Culture Collection (ATCC) (Rockville, MD, USA). Human normal osteoblast cells NHOst were purchasedt from ATCC. miR-125a mimics and miRNA negative control (miR-NC) were designed and synthesized by GenePharma (GenePharma, Shanghai, China). For transfection, $2 \times 10^{5}$ MG-63 and U2OS cells were plated in 6 -well plates $\left(5 \times 10^{5}\right.$ cells per well) and transiently transfected with $100 \mathrm{nM}$ of miR-125a mimics and miRNC using siPORT neoFX Transfection Agent (Ambion, Austin, TX), according to the manufacturer's protocol.

\section{miRNA extraction and quantitative RT-PCR}

Total RNA was extracted from cultured cells or tissues samples with a miRNeasy Mini kit (Qiagen). The cDNA of target miRNA was reverse transcribed from the total RNA using specific miRNA primer and a miScript Reverse Transcription Kit (Qiagen). miR-125a expression was measured with a miScript SYBR Green PCR Kit (Qiagen) using the ABI7500 Real-Time PCR System (Applied Biosystems, Foster City, CA, USA). The mRNA expression levels of E2F2 was measured by qPCR with the ABI 7500 Real-Time PCR System. GAPDH and U6 were used as an internal control.

\section{Western blotting}

Cells were harvested and homogenized with lysis buffer 72 hours after transfection with miR-125a mimic and miR-NC mimics. Total protein was separated by denaturing $15 \%$ sodium dodecyl sulphatepolyacrylamide gel electrophoresis. The membranes were incubated with primary antibodies against 


\section{Cellular Physiology Cell Physiol Biochem 2017;43:768-774 \begin{tabular}{l|l|l} 
and BOI: 10.1159/000481560 & $\begin{array}{l}\text { C } 2017 \text { The Author(s). Published by S. Karger AG, Basel } \\
\text { www.karger.com/cpb }\end{array}$
\end{tabular}}

Tao et al.: MiR-125a Suppresses OS by Inhibiting E2F2

E2F2 (1:500; Cell Signaling, CA, USA) and GAPDH (1:2000; Santa Cruz Biotechnology, Santa Cruz, CA, USA) overnight at $4{ }^{\circ} \mathrm{C}$. After being extensively washed with PBS containing $0.1 \%$ Triton X-100, the membranes were incubated with HRP-conjugated goat anti-rabbit antibody for $30 \mathrm{~min}$ at room temperature. The bands were visualized using an ECL system (Millipore, Billerica, WI, USA).

Plasmid construction and luciferase reporter assay

The expression vector for miR-125a precursor sequence was generated by cloning the PCR product into a pCDH plasmid using the following primers:5'-CGGGATCCTCTTTCTGTCTCTGGCTCTCAGAA-3' (forward) and $5^{\prime}$-CGGAATTCAGTGGTCTGGGGTCAGAGGTCA-3' (reverse). The antisense miR-125a oligonucleotide (anti-hsa-miR-125a) and antisense miRNA control were purchased from Qiagen (Valencia, CA, USA). The E2F2 3'-UTR containing predicted miR-125a binding sites (both wild-type and mutant) were cloned into psiCHECK-2 plasmid. For the luciferase reporter assay, MG-63 cells were transfected with different combinations of miR-125a, miR-NC, psiCHECK-2-E2F2 3'UTR-WT and psiCHECK-2-E2F2 3'UTR-Mut for 24 hours. The relative luciferase activities were evaluated 48 hours later using the Dual-Luciferase Reporter Assay Kit (Promega).

\section{Cell proliferation and invasion assays}

After 24 hours of transfection, cells were harvested and seeded into 96-well plates at a density of $5 \times 10^{3}$ cells per well and cultured in an environment with $5 \% \mathrm{CO} 2$ at $37^{\circ} \mathrm{C}$ for $1,2,3$ and 4 days. Ten microlitres of CCK-8 solution (Dojindo Laboratories, Kumamoto, Japan) was added to the culture medium in each well. After incubation for1 hour, OD values were read using a microplate reader (Bio-Tek Company, Winooski, VT, USA) at 450-nm wavelength. The measurement at each time point was repeated in three wells, and the experiment was independently performed in triplicate. Cell invasion assays used transwell chambers (Corning; Tewksbury, MA, USA) coated with Matrigel (BD Biosciences; San Jose, CA, USA) on the upper surface. Briefly, cells were seeded in the chambers with medium containing $0.1 \% \mathrm{FBS}$, while medium containing $20 \%$ FBS was placed in the lower chambers. Twenty-four hours later, cells had invaded through the Matrigel were fixed with 4\% paraformaldehyde and stained with crystal violet. The number of invaded cells was counted in five randomly selected microscopic fields and photographed.

\section{Statistical analysis}

The correlations between E2F2 expression and clinicopathological characteristics were analysed by $\chi 2$ test. Survival curves were plotted using the Kaplan-Meier method, and the significant difference was analysed by log-rank test. The influence of E2F2 on survival was assessed by the Cox proportional hazards model. Differences between experimental groups were assessed using two-tailed unpaired Student's $\mathrm{t}$ test. Statistical analysis was carried out with Graphpad Prism (version 6.01) (La Jolla, CA, USA) and SPSS 21.0 software (Chicago, IL, USA). A $P$-value of less than 0.05 was considered statistically significant unless specified otherwise.

\section{Results}

miR-125a expression is decreased in osteosarcoma tissues and cell lines

To understand the role of miR-125a in osteosarcoma, miR-125a expression was first detected by qRT-PCR in 65 pairs of osteosarcoma tissues and corresponding normal bone tissues. The relative expression of miR-125a in the cancer tissues normalized to U6 was 1.78 \pm 0.24 (mean $\pm \mathrm{SD}$ ), while the relative expression of miR-125a in adjacent normal tissues was $5.64 \pm 0.32$. miR-125a expression was significantly down-regulated in osteosarcoma tissues compared with that in matched adjacent tissues $(P<0.001$, Fig. $1 \mathrm{~A})$. Moreover, miR125a expression in osteosarcoma cell lines was lower than that of normal osteoblastic cell lines (Fig. 1B).

Association between miR-125a expression and clinicopathological factors

We divided patients into high or low groups according to their median miR-125a expression (1.27). As shown in Table 1, miR-125a expression was only associated with tumor 


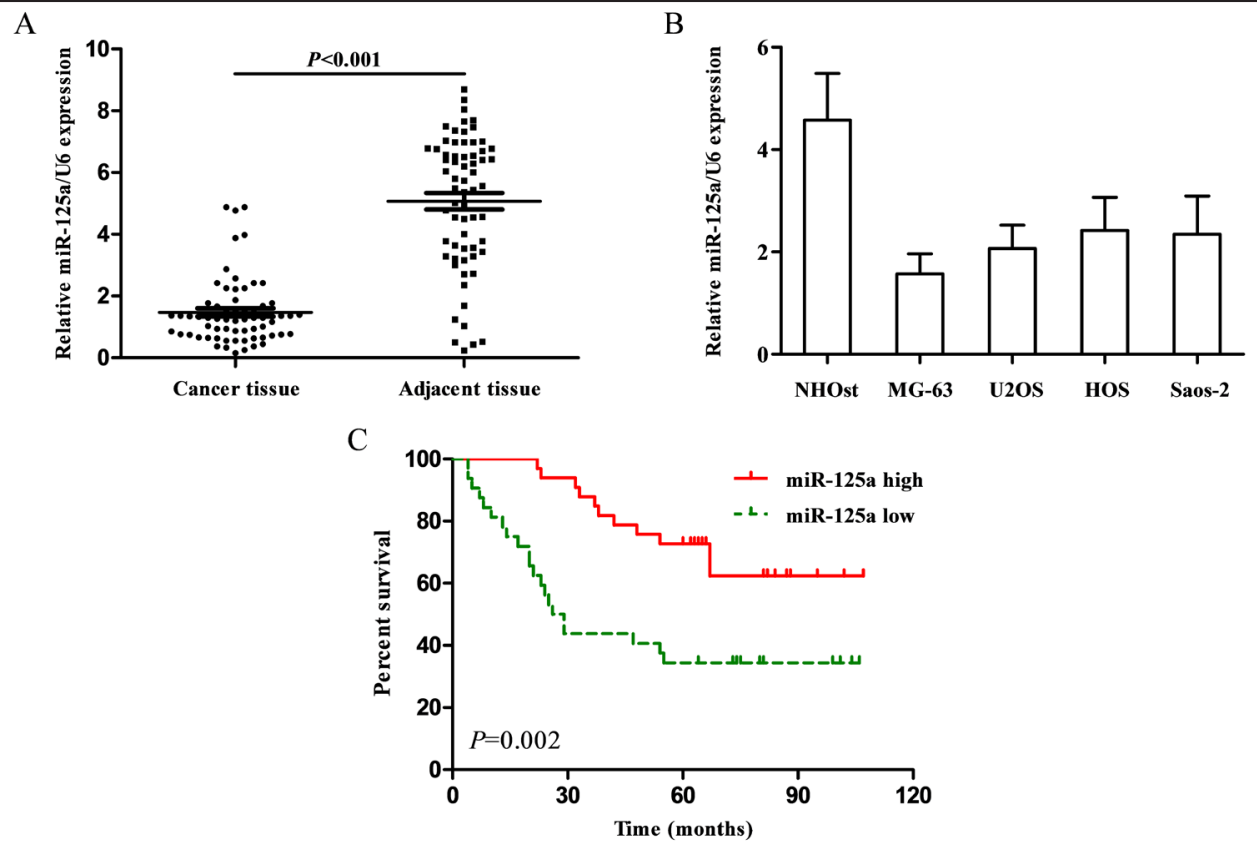

Fig. 1. (A) The expression of miR-125a in 65 paired of osteosarcoma samples and their corresponding normal bone tissues was detected using qRT-PCR; (B) miR-125a expression in human osteosarcoma cell lines (MG-63, U2OS, HOS and Saos-2), and normal osteoblastic cell line NHOst was detected by qRT-PCR; (C) Kaplan-Meier curve for osteosarcoma patients classified as high or low miR-125a expression, the P-value was calculated using the log-rank test.

size $(P=0.001)$. There was no correlation between miR-125a expression and other clinicopathological factors, such as sex, age, histological grade, histological type and tumor stage. Furthermore, patients with low miR-125a expression had poorer overall survival than those with high expression of miR-125a ( $P=0.001$, Fig. 1C). Osteoblastic type, tumor size $>8 \mathrm{~cm}$, stage III, and low miR-125a expression were poor prognostic factors by Cox regression univariate analyses $(P<0.05$, Table 2). In Cox regression multivariate analyses, tumor stage and miR-125a expression were independent prognostic factors (Table 2).

\section{miR-125a suppresses osteosarcoma cell} proliferation

To investigate the biological functions of miR-125a in osteosarcoma cell, we upregulated miR-125a expression in MG-63 and U2OS cells (Fig. 2A, 2B). Overexpression of miR-125a significantly inhibited the growth of MG-63 and U2OS cell (Fig. 2C, 2D). We also examined the effect of miR-125a on the invasive abilities of osteosarcoma
Table 1. The relationship between clinicopathological characteristics and miR-125a expression in osteosarcoma

\begin{tabular}{lcccc}
\hline & \multirow{2}{*}{ Case (65) miR-125a expression } & \\
\cline { 3 - 5 } & & High (33) & Low (32) & p \\
\hline Sex & 31 & 18 & 13 & \\
Male & 34 & 15 & 19 & \\
Female & & & & 0.515 \\
Age & 27 & 15 & 12 & \\
$<20$ & 38 & 18 & 20 & \\
$\geq 20$ & & & & 0.635 \\
Histological grade & 14 & 7 & 7 & \\
Well differentiated & 16 & 9 & 7 & \\
Moderately differentiated & 16 & 6 & 10 & \\
Poorly differentiated & 19 & 11 & 8 & \\
Undifferentiated & 19 & & & 0.649 \\
Histological type & & & 23 & \\
Osteoblastic & 45 & 22 & 23 & \\
Others & 20 & 11 & 9 & \\
Tumor size & & & & $0.001^{*}$ \\
$\leq 8 \mathrm{~cm}$ & 41 & 27 & 14 & \\
$>8 \mathrm{~cm}$ & 24 & 6 & 18 & \\
Tumor stage & & & & 0.256 \\
I+ II & 29 & 17 & 12 & \\
III & 36 & 16 & 20 & \\
\hline
\end{tabular}


cell lines. However, miR-125a overexpression could not inhibite invasion in MG-63 and U20S cells as shown by transwell analysis. Collectively, our data showed that miR-125a suppresses osteosarcoma cell growth but not cell invasion.

$$
\begin{array}{lr}
\text { miR-125a } & \text { suppresses } \\
\text { osteosarcoma } \\
\text { proliferation } \\
\text { targeting E2F2 }
\end{array}
$$$$
\text { To investigate the }
$$
mechanisms by which miR-125a modulates cell proliferation, miRBase (http://www.mirbase. org) was used to predict the potential targets of miR-125a. Among the candidate target genes, E2F2 was found to have a miR-125a binding site in its $3^{\prime}$ UTR. To validate whether E2F2 has a binding site for miR-125a,

\begin{tabular}{|c|c|c|c|c|}
\hline \multirow{2}{*}{ Variables } & \multicolumn{2}{|c|}{ Univariate analysis } & \multicolumn{2}{|c|}{ Multivariate analysis } \\
\hline & $\mathrm{HR}(95 \% \mathrm{Cl})$ & $P$ value & HR $(95 \% \mathrm{Cl})$ & $P$ value \\
\hline \multicolumn{5}{|l|}{ Sex } \\
\hline Male vs. Female & $1.16(0.58-2.34)$ & 0.679 & & \\
\hline \multicolumn{5}{|l|}{ Age } \\
\hline$\geqslant 20$ years vs. $<20$ years & $0.95(0.47-1.91)$ & 0.887 & & \\
\hline Histological grade & & 0.120 & & \\
\hline Well differentiated & Ref. & - & & \\
\hline Moderately differentiated & $0.50(0.16-1.57)$ & 0.233 & & \\
\hline Poorly or not differentiated & $1.70(0.67-4.49)$ & 0.253 & & \\
\hline Undifferentiated & $2.23(0.58-6.34)$ & 0.237 & & \\
\hline \multicolumn{5}{|l|}{ Histological type } \\
\hline Osteoblastic vs. other & $2.40(1.13-5.08)$ & $0.022^{*}$ & $1.88(0.87-4.04)$ & 0.108 \\
\hline \multicolumn{5}{|l|}{ Tumor size } \\
\hline$>8 \mathrm{~cm}$ vs. $\leq 8 \mathrm{~cm}$ & $2.21(1.10-4.45)$ & $0.026^{*}$ & $1.86(0.89-3.89)$ & 0.099 \\
\hline \multicolumn{5}{|l|}{ Tumor stage } \\
\hline III vs. I+II & $3.88(1.36-11.08)$ & $0.011^{*}$ & $3.32(1.13-9.73)$ & $0.029^{*}$ \\
\hline \multicolumn{5}{|l|}{ miR-125a } \\
\hline Low vs. High & $3.05(1.46-6.34)$ & $0.003^{*}$ & $2.39(1.11-5.17)$ & $0.027^{*}$ \\
\hline
\end{tabular}
the effects of miR-125a mimic or
Table 2. Univariate and multivariate cox regression analyses for overall survival in patients with osteosarcoma

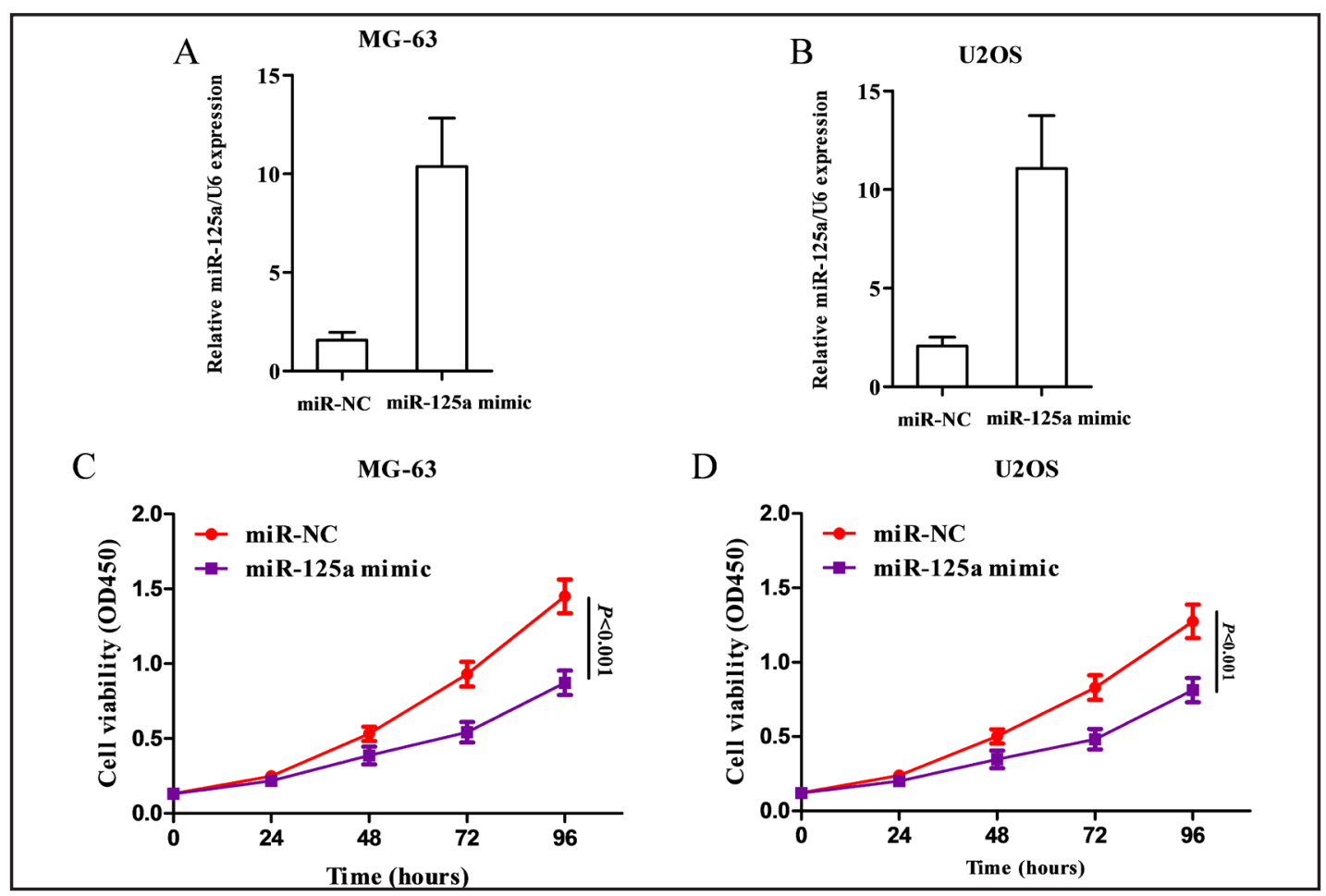

Fig. 2. (A) MG-63 and (B) U2OS cells were transfected with hsa-miR-125a mimics or negative control (NC). The expression of miR-125a was confirmed by qRT-PCR in both MG-63 and U2OS cell lines. Overexpression of miR-125a inhibits (C) MG-63 or (D) U20S proliferation. Cell proliferation was measured by a CCK-8 assay at the indicated time. 


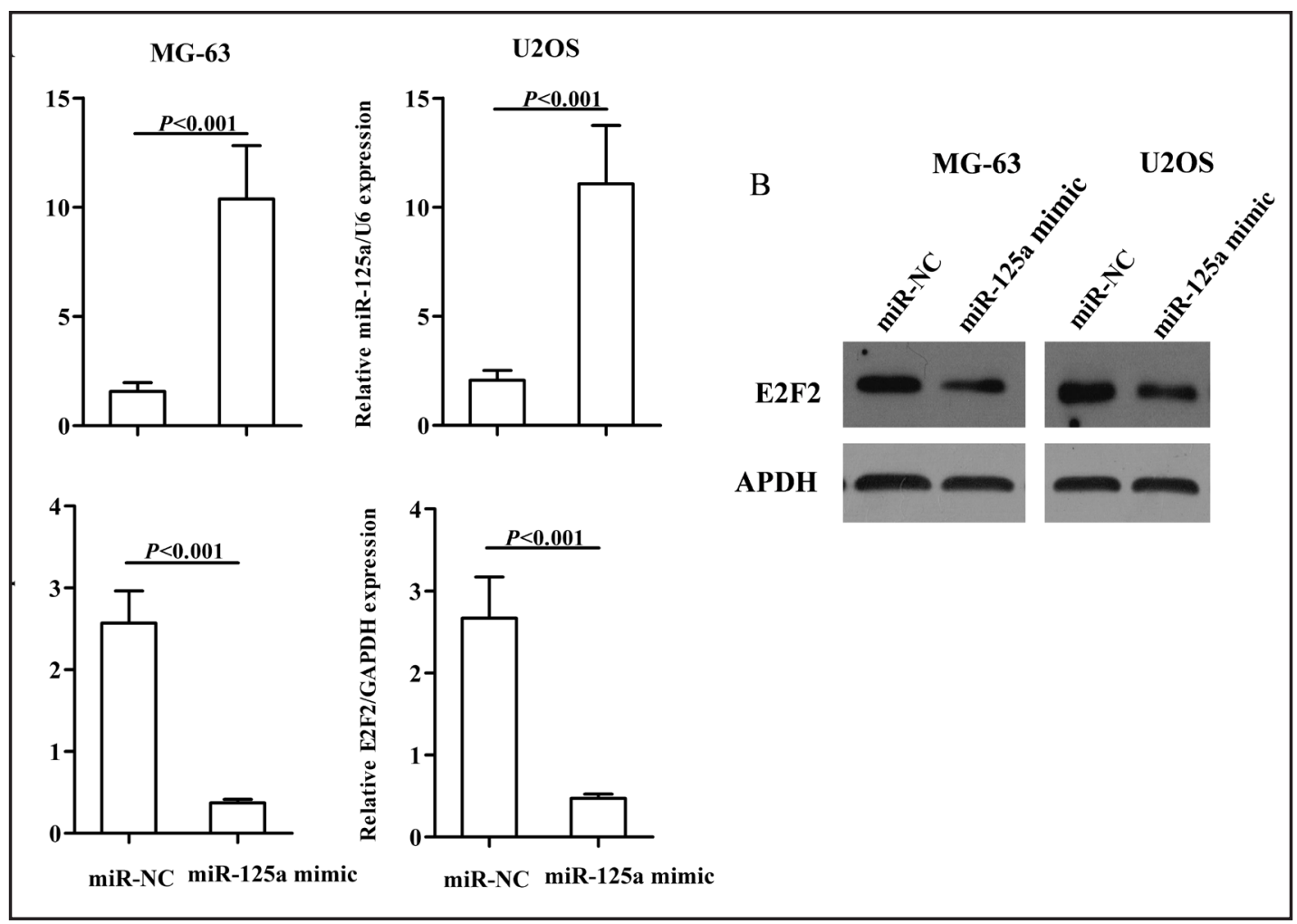

Fig. 3. The mRNA levels of E2F2 in (A) MG-63 and U2OS cells were examined by qRT-PCR after transfected with miR-125a mimics or negative control (NC). The protein levels of E2F2 in (B) MG-63 and U20S cells were examined by western blot after transfected with miR-125a mimics or negative control (NC).

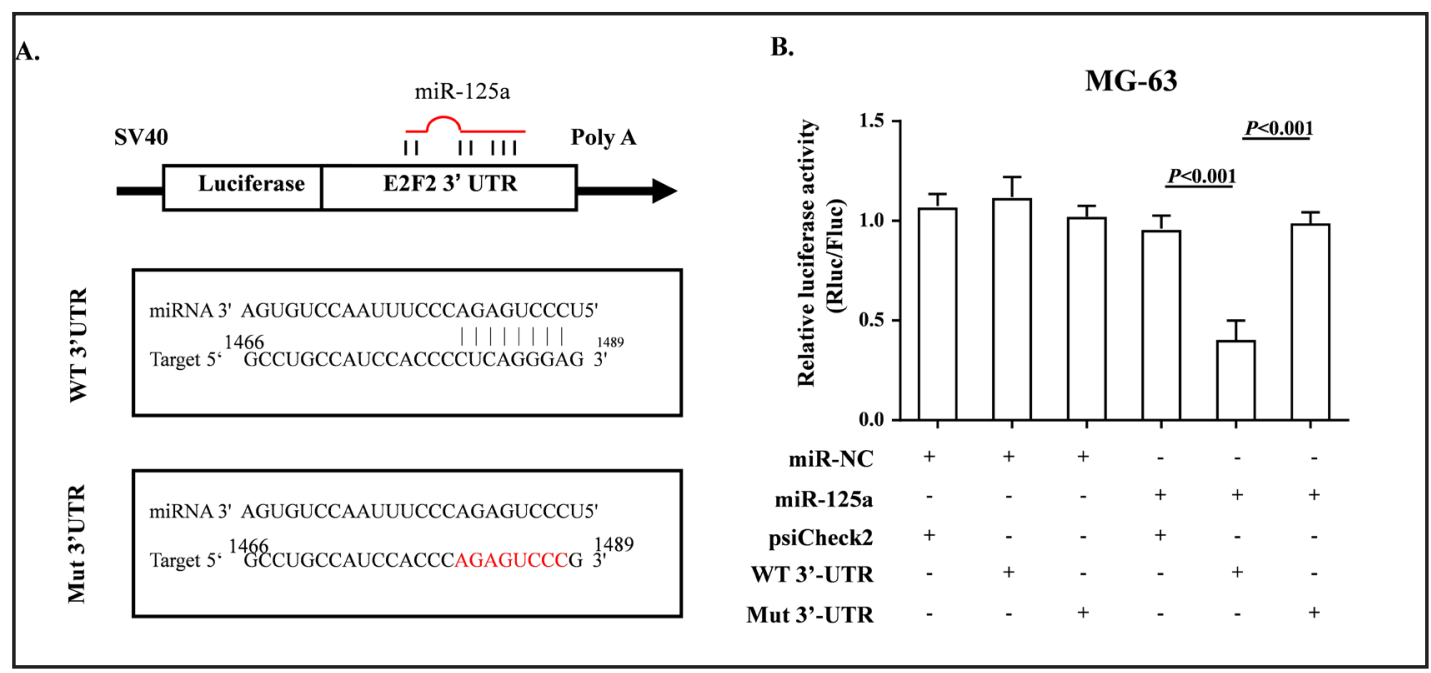

Fig. 4. A. The construction of psiCheck 2 report plasmid, containing wild type or mutant E2F2 3'-UTR. B. The luciferase assay of MG-63 cells transfected with E2F2 3'UTR luciferase vectors, and miR-125a or miR-NC control. The luciferase activity was measured at $24 \mathrm{~h}$ after transfection.

miR-NC on E2F2 mRNA and protein expression levels in osteosarcoma cells were examined. Overexpression of miR-125a in MG-63 and U2OS cells resulted in a reduction of E2F2 mRNA and protein expression (Fig. 3). To validate whether miR-125a directly targets E2F2, we cloned wild-type and mutant 3'UTR (the miR-125a binding site was mutated) of E2F2 into the psiCheck-2 luciferase reporter vector (Fig. 4A) and performed luciferase assay in MG- 
63 cells. The results showed that miR-125a substantially inhibited the luciferase reporter activity of the wild-type 3'UTR but not that of the mutated E2F2 3'-UTR (Fig. 4B). Therefore, our results demonstrate that E2F2 is a direct target of miR125a in MG-63 cells.

To further confirm whether miR125a functionally targets E2F2 in regulating cell proliferation, we cotransfected osteosarcoma cells with miR-125a or E2F2 overexpression vectors or both, and measured their growth rate. The growth of cells transfected with miR-125a was significantly slower than that of controls, while the cells transfected with E2F2 showed the opposite results (Fig. 5). Interestingly, E2F2 overexpression could completely rescue the suppressed proliferation mediated by miR-125a in both cell lines, suggesting that miR-125a inhibited cell growth through E2F2 (Fig. 5).

\section{Discussion}

Studies have suggested that miR125 a can inhibit the tumor growth and play a tumor-suppressive role $[7-11,14]$. miR-125a has a low expression in a variety of tumors [7-

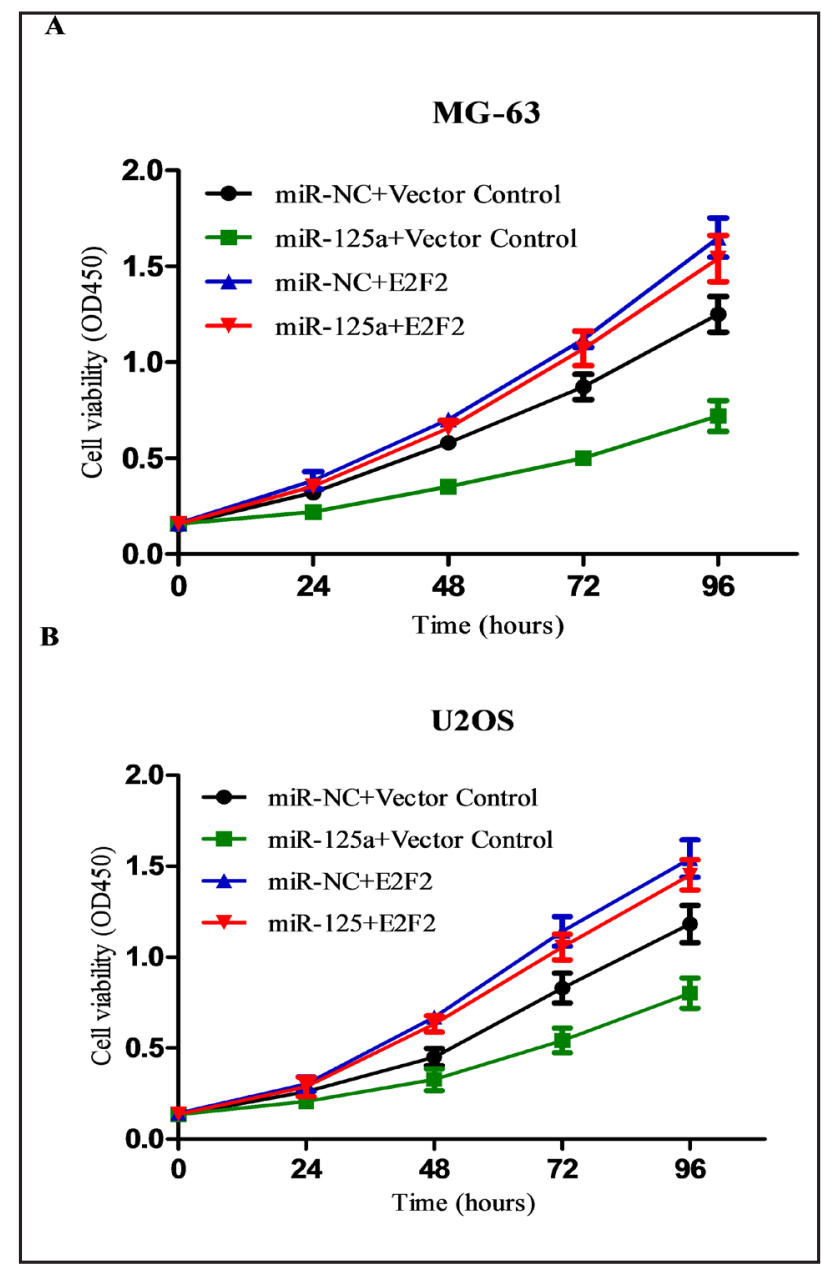

Fig. 5. The viability of (A) MG-63 and (B) U2O2 cells was detected from $0 \mathrm{~h}$ to 96 hours after transfection with miR$\mathrm{NC}+$ Vector control, miR-125a+Vector control, miR-NC+E2F2 or miR-125a+E2F2. $11]$, but its expression and function in osteosarcoma have not been studied. It was demonstrated for the first time in this study that the expression of miR-125a expression in osteosarcoma is significantly lower than that in normal para-carcinoma tissues, which is closely related to the tumor size. Further analysis of the relationship between miR-125a and overall survival showed that the survival of patients in high miR-125a expression was significantly longer than that of patients with low miR-125a expression, and multivariate analysis suggested that miR-125a is an independent prognostic factor for osteosarcoma patients. In addition, it was found in this study that miR-125a can inhibit the growth of osteosarcoma cells. The dual-luciferase reporter assay demonstrated that E2F2 is a novel target gene for miR-125a. In addition, in a recovery experiment, it was shown that miR-125a inhibits the biological function of osteosarcoma cells by inhibiting the expression of E2F2, revealing a new mechanism by which miR-125a regulates osteosarcoma cell growth through E2F2.

miR-125a expression is significantly reduced in osteosarcoma tissues, mainly due to the following two reasons: 1) miR-125a gene is located on chromosome 19q13.41, and the mutation or deletion of the chromosomal region or loss of upstream promoter region may be one of the reasons for decreased miR-125a transcription; 2) promoter methylation is an important regulatory mechanism of gene transcription. The increased methylation of miR- 
125a promoter may lead to a decrease in transcription factor recruitment to the promoter, thus resulting in a decrease in the expression of miR-125a. Previous studies have shown that miR-125a plays a role as a tumor suppressor genes in prostate cancer [15], glioblastoma [16, 17], breast cancer [18], liver cancer [7, 19], gastric cancer [11, 20] and cervical cancer [21, $22]$. Wang et al. found that EGFR inhibited the invasion of lung cancer cells by activating miR$125 \mathrm{a}$, and miR-125a could also inhibit the proliferation of vascular endothelial cells [23]. In breast cancer, miR-125a is significantly down-regulated and displays the anti-tumor effect via ERBB2 and ERBB3 signaling pathways [24, 25]. Exogenous expression of miR-125a can significantly inhibit the proliferation and metastasis of pancreatic cancer cells [26]. miR-125a can inhibit the malignant transformation of pancreatic cancer cells by targeted regulation of MMP11 and VEGF-A [26].

The E2F family is a group of important transcription factors that regulate cell cycle and apoptosis and is widely involved in the tumorigenesis of various cancer types. It plays an important role in cell proliferation and cell cycle regulation [27]. E2F2 is a member of the E2F transcription factor family, which functions as a proto-oncogenes, and its increased expression can promote the proliferation of tumor cells. It mainly binds to the retinoblastoma protein, Prb, in a cell cycle-dependent manner to regulate downstream cell cycle and expression of proliferation-associated proteins [28]. In addition, E2F1 and E2F2 maintain the steady state of cells together with p53 protein, and an imbalance in these proteins leads to tumorigenesis [29]. Besides, E2F2 can promote cell transformation by regulating G1 to S phase transition [30].

In our study, we combined clinical and experimental studies to demonstrate a critical role of miR-125a in osteosarcoma. We found that miR-125a expression was low in osteosarcoma tissue and cells. Osteosarcoma patients with high miR-125a expression exhibit poor survival. miR-125a has a potent inhibitory effect on osteosarcoma cell proliferation. In addition, E2F2 is a direct target of miR-125a in osteosarcoma, and the suppressed cell proliferation mediated by miR-125a can be rescued by the restoration of E2F2 expression. Our work led to the identification of a novel functional pathway controlled by miR-125a and its direct target, E2F2, in osteosarcoma. Therefore, miR-125a may represent a novel therapeutic target for the treatment of osteosarcoma.

\section{Disclosure Statement}

The authors have no conflict of interest.

\section{References}

1 Luetke A, Meyers PA, Lewis I, Juergens H: Osteosarcoma treatment - where do we stand? A state of the art review. Cancer Treat Rev 2014;40:523-532.

-2 Geller DS, Gorlick R: Osteosarcoma: a review of diagnosis, management, and treatment strategies. Clin Adv Hematol Oncol 2010;8:705-718.

- G Gelderblom H, Jinks RC, Sydes M, Bramwell VH, van Glabbeke M, Grimer RJ, Hogendoorn PC, McTiernan A, Lewis IJ, Nooij MA, Taminiau AH, Whelan J: Survival after recurrent osteosarcoma: data from 3 European Osteosarcoma Intergroup (EOI) randomized controlled trials. Eur J Cancer 2011;47:895-902.

4 Jaffe N, Gorlick R: High-dose methotrexate in osteosarcoma: let the questions surcease--time for final acceptance. J Clin Oncol 2008;26:4365-4366.

5 Di Leva G, Croce CM: miRNA profiling of cancer. Curr Opin Genet Dev 2013;23:3-11.

6 Kushlinskii NE, Fridman MV, Braga EA: Molecular Mechanisms and microRNAs in Osteosarcoma Pathogenesis. Biochemistry (Mosc) 2016;81:315-328.

7 Bi Q, Tang S, Xia L, Du R, Fan R, Gao L, Jin J, Liang S, Chen Z, Xu G, Nie Y, Wu K, Liu J, Shi Y, Ding J, Fan D: Ectopic expression of MiR-125a inhibits the proliferation and metastasis of hepatocellular carcinoma by targeting MMP11 and VEGF. PLoS One 2012;7:e40169. 


\section{Cellular Physiology Cell Physiol Biochem 2017;43:768-774 \begin{tabular}{l|l|l} 
and Biochemistry Publ: 10.1159/000481560 & $\begin{array}{l}\text { (c) } 2017 \text { The Author(s). Published by S. Karger AG, Basel } \\
\text { www.karger.com/cpb }\end{array}$
\end{tabular}

8 Cowden Dahl KD, Dahl R, Kruichak JN, Hudson LG: The epidermal growth factor receptor responsive miR125a represses mesenchymal morphology in ovarian cancer cells. Neoplasia 2009;11:1208-1215.

-9 Li W, Duan R, Kooy F, Sherman SL, Zhou W, Jin P: Germline mutation of microRNA-125a is associated with breast cancer. J Med Genet 2009;46:358-360.

10 Shang H, Wang T, Shang F, Huang KM, Li YQ: A germline mutation in the miR125a coding region reduces miR125a expression and is associated with human gastric cancer. Mol Med Rep 2014;10:1839-1844.

11 Xu Y, Huang Z, Liu Y: Reduced miR-125a-5p expression is associated with gastric carcinogenesis through the targeting of E2F3. Mol Med Rep 2014;10:2601-2608.

12 Li G, Li J, Li C, Qi H, Dong P, Zheng J, Yu F: MicroRNA-125a-5p Contributes to Hepatic Stellate Cell Activation through Targeting FIH1. Cell Physiol Biochem 2016;38:1544-1552.

13 Ma JF, Zang LN, Xi YM, Yang WJ, Zou D: MiR-125a Rs12976445 Polymorphism is Associated with the Apoptosis Status of Nucleus Pulposus Cells and the Risk of Intervertebral Disc Degeneration. Cell Physiol Biochem 2016;38:295-305.

14 Pan Q Liao X, Liu H, Wang Y, Chen Y, Zhao B, Lazartigues E, Yang Y, Ma X: MicroRNA-125a-5p alleviates the deleterious effects of ox-LDL on multiple functions of human brain microvessel endothelial cells. Am J Physiol Cell Physiol 2017;312:C119-C130.

15 Fu Y, Cao F: MicroRNA-125a-5p regulates cancer cell proliferation and migration through NAIF1 in prostate carcinoma. Onco Targets Ther 2015;8:3827-3835.

-16 Yuan J, Xiao G, Peng G, Liu D, Wang Z, Liao Y, Liu Q, Wu M, Yuan X: MiRNA-125a-5p inhibits glioblastoma cell proliferation and promotes cell differentiation by targeting TAZ. Biochem Biophys Res Commun 2015;457:171-176.

-17 Cortez MA, Nicoloso MS, Shimizu M, Rossi S, Gopisetty G, Molina JR, Carlotti C, Jr., Tirapelli D, Neder L, Brassesco MS, Scrideli CA, Tone LG, Georgescu MM, Zhang W, Puduvalli V, Calin GA: miR-29b and miR-125a regulate podoplanin and suppress invasion in glioblastoma. Genes Chromosomes Cancer 2010;49:981-990.

-18 Hsieh TH, Hsu CY, Tsai CF, Long CY, Chai CY, Hou MF, Lee JN, Wu DC, Wang SC, Tsai EM: miR-125a-5p is a prognostic biomarker that targets HDAC4 to suppress breast tumorigenesis. Oncotarget 2015;6:494-509.

19 Tang H, Li RP, Liang P, Zhou YL, Wang GW: miR-125a inhibits the migration and invasion of liver cancer cells via suppression of the PI3K/AKT/mTOR signaling pathway. Oncol Lett 2015;10:681-686.

20 Nishida N, Mimori K, Fabbri M, Yokobori T, Sudo T, Tanaka F, Shibata K, Ishii H, Doki Y, Mori M: MicroRNA125a-5p is an independent prognostic factor in gastric cancer and inhibits the proliferation of human gastric cancer cells in combination with trastuzumab. Clin Cancer Res 2011;17:2725-2733.

21 Fan Z, Cui H, Xu X, Lin Z, Zhang X, Kang L, Han B, Meng J, Yan Z, Yan X, Jiao S: MiR-125a suppresses tumor growth, invasion and metastasis in cervical cancer by targeting STAT3. Oncotarget 2015;6:25266-25280.

-22 Fan Z, Cui H, Yu H, Ji Q, Kang L, Han B, Wang J, Dong Q, Li Y, Yan Z, Yan X, Zhang X, Lin Z, Hu Y, Jiao S: MiR125a promotes paclitaxel sensitivity in cervical cancer through altering STAT3 expression. Oncogenesis 2016;5:e223.

23 Wang G, Mao W, Zheng S, Ye J: Epidermal growth factor receptor-regulated miR-125a-5p--a metastatic inhibitor of lung cancer. FEBS J 2009;276:5571-5578.

-24 Wang S, Huang J, Lyu H, Lee CK, Tan J, Wang J, Liu B: Functional cooperation of miR-125a, miR-125b, and miR-205 in entinostat-induced downregulation of erbB2/erbB3 and apoptosis in breast cancer cells. Cell Death Dis 2013;4:e556.

25 Scott GK, Goga A, Bhaumik D, Berger CE, Sullivan CS, Benz CC: Coordinate suppression of ERBB2 and ERBB3 by enforced expression of micro-RNA miR-125a or miR-125b. J Biol Chem 2007;282:1479-1486.

26 Bloomston M, Frankel WL, Petrocca F, Volinia S, Alder H, Hagan JP, Liu CG, Bhatt D, Taccioli C, Croce CM: MicroRNA expression patterns to differentiate pancreatic adenocarcinoma from normal pancreas and chronic pancreatitis. JAMA 2007;297:1901-1908.

-27 Xanthoulis A, Tiniakos DG: E2F transcription factors and digestive system malignancies: how much do we know? World J Gastroenterol 2013;19:3189-3198.

-28 Evangelou K, Havaki S, Kotsinas A: E2F transcription factors and digestive system malignancies: how much do we know? World J Gastroenterol 2014;20:10212-10216.

-29 Iglesias-Ara A, Zenarruzabeitia O, Buelta L, Merino J, Zubiaga AM: E2F1 and E2F2 prevent replicative stress and subsequent p53-dependent organ involution. Cell Death Differ 2015;22:1577-1589.

-30 Zhu W, Giangrande PH, Nevins JR: E2Fs link the control of G1/S and G2/M transcription. EMBO J 2004;23:4615-4626. 